\title{
Transformer Magnetizing Inrush Currents Using a Directly Coupled Voltage-Source Inverter
}

\author{
Rickard Ekström, Senad Apelfröjd, and Mats Leijon \\ Division of Electricity, Department of Engineering Physics, Swedish Centre for Renewable Electric Energy Conversion, \\ Uppsala University, P.O. Box 534, 75121 Uppsala, Sweden
}

Correspondence should be addressed to Rickard Ekström; rickard.ekstrom@angstrom.uu.se

Received 20 July 2013; Accepted 19 September 2013

Academic Editors: J. Abu Qahouq and J. Doval-Gandoy

Copyright (C) 2013 Rickard Ekström et al. This is an open access article distributed under the Creative Commons Attribution License, which permits unrestricted use, distribution, and reproduction in any medium, provided the original work is properly cited.

\begin{abstract}
The connection of a power transformer to the grid is associated with magnetizing inrush currents that may result in power quality issues as well as faulty relay tripping. In distributed generation, the transformer may instead be premagnetized from the source to avoid this. In this paper, a VSI is directly coupled to a transformer. Three different strategies of premagnetization are implemented into the control system, and the inrush currents are measured for various values of the remanent flux in the core. The results show good reduction in the peak magnetizing inrush currents without using any external circuitry.
\end{abstract}

\section{Introduction}

When energizing a power transformer, the magnetizing inrush currents that follow may be several times higher than the rated currents for the transformer. The magnitude of the inrush currents may cause voltage dips in the local grid, resulting in poor power quality [1]. Also, the magnetizing inrush currents are rich in harmonic content, usually have a high direct current component, and may erroneously trigger transformer overcurrent protections [2]. Much work has been conducted in making the protective relays recognize the difference between overcurrents at a fault and a magnetizing inrush current [3].

The magnitude of the inrush currents depends on the circuit reactance, the phase angle $\alpha$ of the voltage source, and the transformer remanent magnetic flux $\phi_{r}$. The remanent flux in the transformer is the flux that exists in the transformer after it is powered down. This phenomenon has long been studied, and various methods and models can be found in the literature. To measure the remanent flux is not easy but may be approximated with measurements of the voltage integral during deenergization.

Several ways to reduce or eliminate the inrush currents have been presented. Ways to handle the issues are through controlled switching and removal of remanent flux $[4,5]$, sequential phase energization $[6,7]$, insertion of damping resistors [8], capacitive loading, or thyristor switching control [9].

Work that uses PWM inverters to inject a cancelling-out current via the inverter during powerup of the transformer has also been presented [10] along with methods to detect the remanent flux by analysing the DC component during switching [11].

Many renewable energy sources are nonsynchronous with the grid, which will require a power electronics conversion stage for grid connection. A commonly used conversion is the voltage-source inverter (VSI), followed by an LCL-filter and a step-up transformer. The full control of the VSI allows the transformer magnetization to be handled by the source rather than the grid, which can give a great advantage in handling the magnetizing inrush currents.

In this paper, the power transformer is directly magnetized by a VSI. The LCL filter is put on the secondary side of the transformer to reduce the ampacity of the filter inductors, as discussed in [12]. No external circuitry is required for the transformer magnetization. Three different strategies of magnetization are experimentally evaluated with variations in the remanent flux, and the peak inrush currents are detected. 


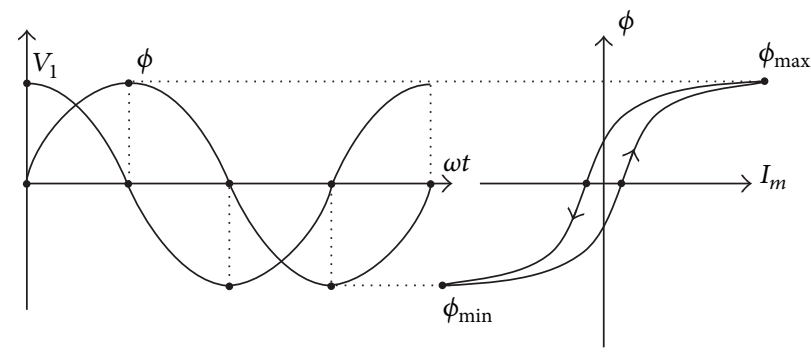

FIGURE 1: The induced core flux $\phi(t)$ lags the induced voltage $v_{1}(t)$ by almost $90^{\circ}$. The resultant magnetizing current $I_{m}$ grows rapidly when the transformer goes into saturation.

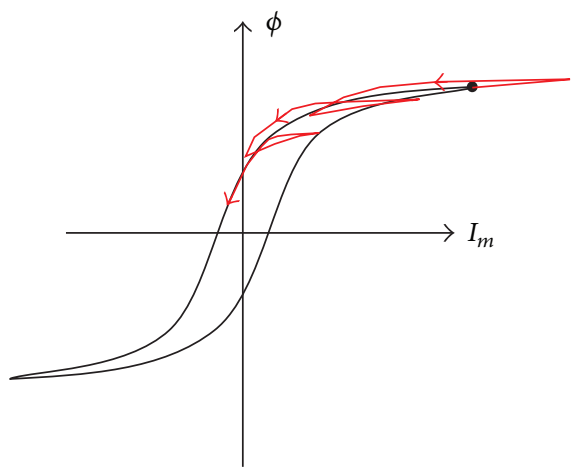

(a) Strategy 1

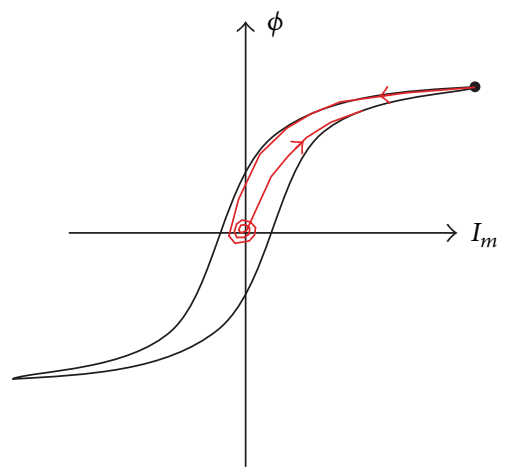

(b) Strategy 2

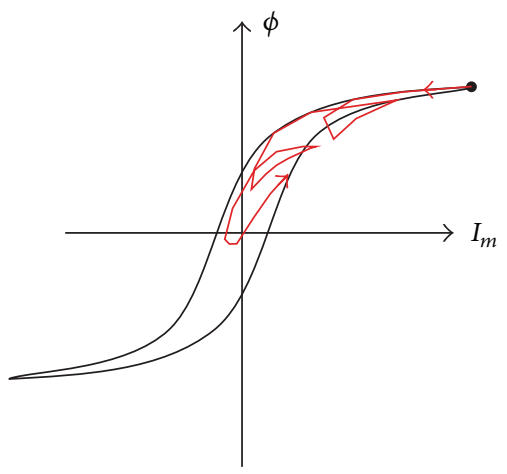

(c) Strategy 3

FIGURE 2: Three different typical paths in the B-H plane. $\phi_{r}$ is assumed to be maximum for all cases. In strategy 1 , the core is directly pushed into saturation and it can take a long time before it stabilizes. In strategy $2, \phi_{r}$ is pulled down to zero for all phases, which reduces the magnitude of the inrush current. In strategy 3 , the voltage ramping will slowly converge to the stable B-H-path while avoiding large inrush currents.

\section{Theory}

When a variable voltage source $v_{1}(t)$ is applied to the transformer windings, a resulting flux $\phi(t)$ will be induced in the transformer core according to Faraday's law as follows:

$$
v_{1}(t)=\sqrt{2}\left|v_{1}\right| \cos (\omega t+\alpha)=N \frac{d \phi(t)}{d t},
$$

where $\omega$ is the natural frequency of the applied voltage, $\alpha$ is the start angle, and $N$, the number of winding turns. The induced flux may be derived by computing the voltage integral over time as follows:

$$
\phi(t)=\int_{t_{1}}^{t_{2}} \frac{v_{1}(t)}{N_{1}} d t=\frac{\sqrt{2}\left|v_{1}\right|}{\omega N_{1}} \sin (\omega t)+\phi_{r},
$$

where $\phi_{r}$ is the remanent flux. Figure 1 shows how this is used to derive the classical $\phi-I_{m}$-curve or $B$-H-curve. It is clear how even a small saturation in the magnetic flux may result in a large magnitude of the magnetizing current $I_{m}$. As a worst case scenario, the peak amplitude of $I_{m}$ may be approximated by [1]

$$
\widehat{I}_{m}=\frac{1}{X+X_{p}+X_{c}(\min )} \quad[\mathrm{pu}],
$$

where $X$ is the source impedance, $X_{p}$ is the winding impedance, and $X_{c}(\mathrm{~min})$ is the minimum magnetization impedance. When the core is completely saturated, it may be treated as an air core, and it has been shown that $X_{c}$ may be approximated by the short-circuit impedance $X_{\mathrm{SC}}$ [13].

More accurately, the magnetizing inrush current is calculated by

$$
\widehat{I}_{m}=\frac{\sqrt{2}\left|v_{1}\right|}{\sqrt{(\omega L)^{2}}+R^{2}} \cdot\left(\frac{2 B_{N}+B_{R}-B_{S}}{B_{N}}\right),
$$

where $B_{N}$ is the normal rated flux density, $B_{r}$ is the remanent flux density, and $B_{S}$ is the saturation flux density. For more detailed analysis, a finite-element method (FEM) model has to be set up for the transformer.

\section{Magnetizing Strategies}

With the VSI directly connected to the power transformer, three different magnetization strategies have been evaluated for start-up of the transformer:

(1) step response with remanent flux,

(2) step response without remanent flux,

(3) voltage ramping with remanent flux.

The general plots of the B-H-curves for the different strategies are illustrated in Figure 2, but they should only be 


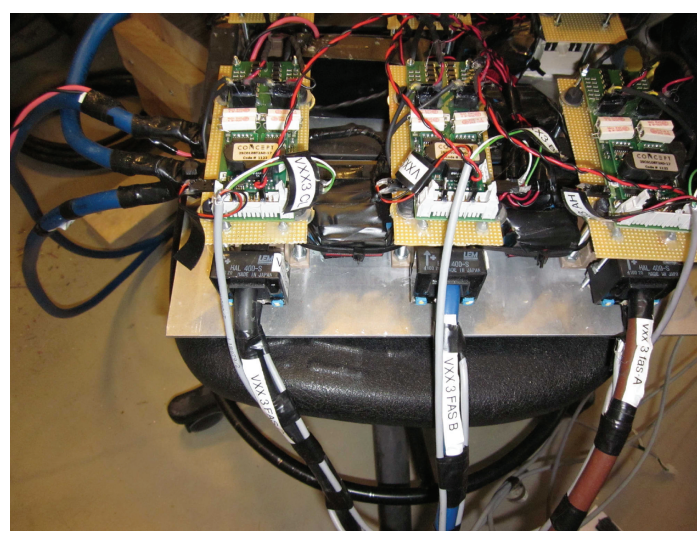

(a) VSI

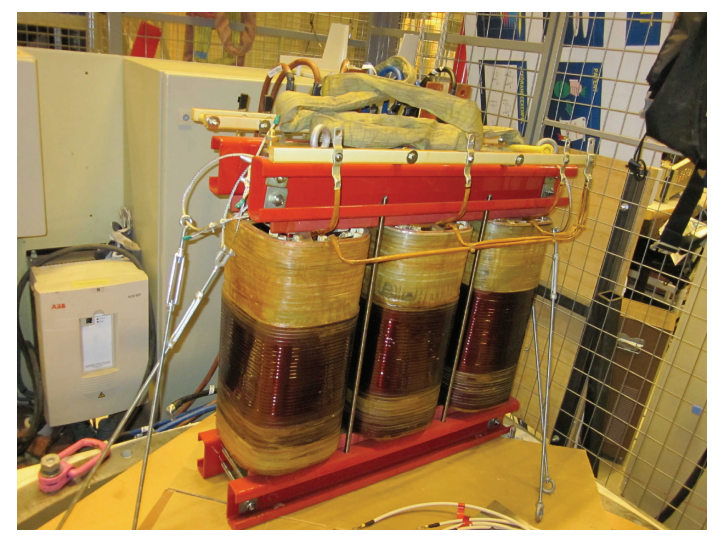

(b) Power transformer

FIGURE 3: The VSI and the power transformer used in the experimental set-up.

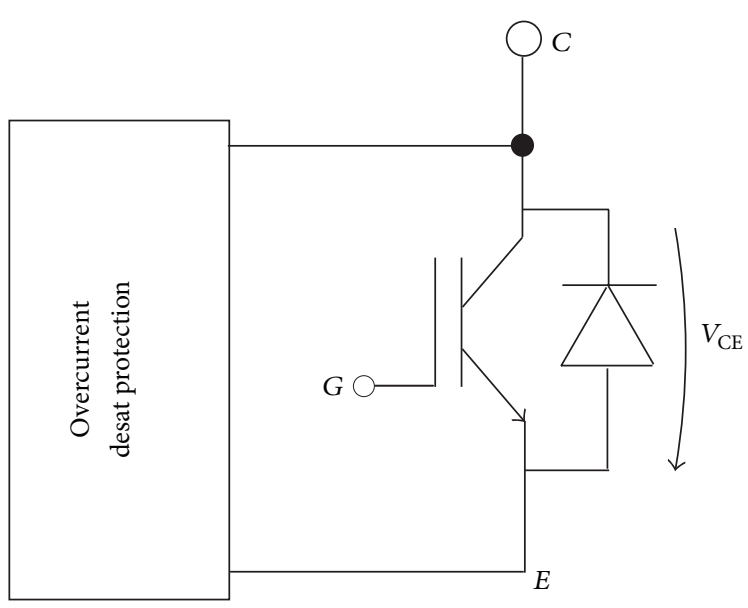

(a)

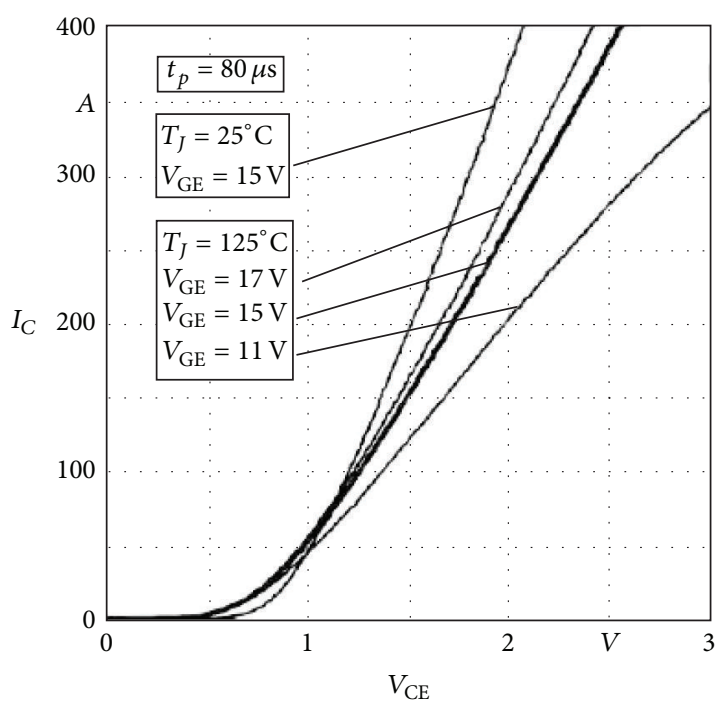

(b)

Figure 4: (a) De-sat protection circuit. (b) $V_{\mathrm{CE}}$ vs. $I_{C}$ from datasheet.

considered as rough estimates. To vary the remanent flux over the entire range, the transformer is magnetized at $1 \mathrm{pu}$ and then abruptly stopped at different angles $\beta$ of the applied voltage. Stopping at $\beta=0^{\circ}$ results in a maximum negative flux $\phi_{\max ,-}$, and stopping at $\beta=180^{\circ}$ results in a maximum positive flux $\phi_{\max ,+} \cdot$

In the first strategy, the inverter is started abruptly, giving full magnetization to the transformer. This becomes similar to an immediate grid connection and will be used as a reference case. In Figure 2(a), the remanent flux was positive at startup, and the transformer core is pushed into saturation as the starting angle $\alpha=0^{\circ}$. If instead $\alpha=180^{\circ}$ for this case, a minimal inrush current would have been obtained for this phase.

In the second strategy, the inverter is started at zero amplitude modulation $m_{a}$, which will slowly force the core flux to zero for all the transformer legs. The switching frequency of the inverter is much faster than the transformer time constant, resulting in only a small pulse ripple in the transformer core flux. This essentially results in a removal of the remanent flux, that is, $\phi_{r}=0$, and becomes a special case of strategy 1 when $\alpha=90^{\circ}$ or $270^{\circ}$. Once the transformer has settled, a step response is made in the induced voltage to $1 \mathrm{pu}$. This is illustrated in Figure 2(b) where the flux is forced to circle around origo before energization.

The third strategy starts at $m_{a}=0$ and slowly increases the applied voltage with a constant ramping function until full magnetization is reached in the transformer core. The applied voltage can be described as

$$
v_{1}(t)=v_{N} \frac{t-t_{0}}{T_{R}} \cos \left(\omega\left(t-t_{0}\right)+\alpha\right) \quad t_{0} \leq t \leq T_{R},
$$

where $v_{N}$ is the nominal voltage, $T_{R}$ is the slope of the ramp, and $t-t_{0}$ is the duration of the voltage ramping. The major benefit of this method is that it becomes rather insensitive to the initial $\phi_{r}$, and the core flux will smoothly settle 


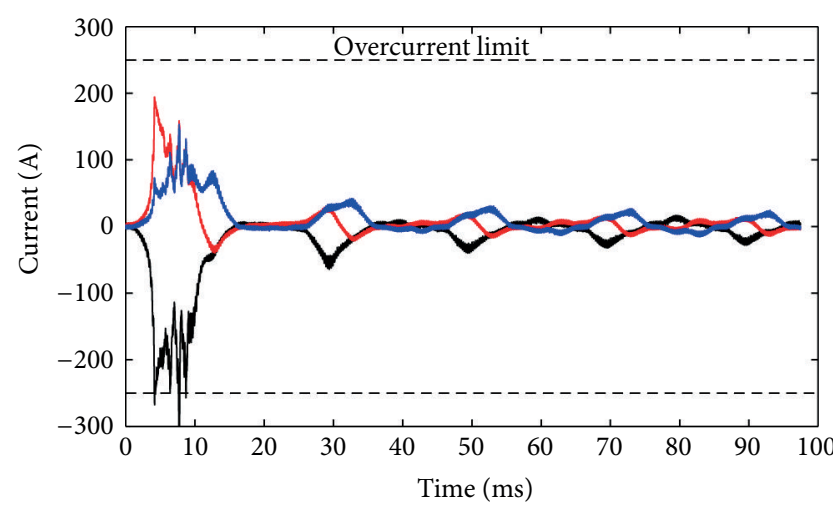

(a) $\alpha=180^{\circ} ; \beta=0^{\circ}$

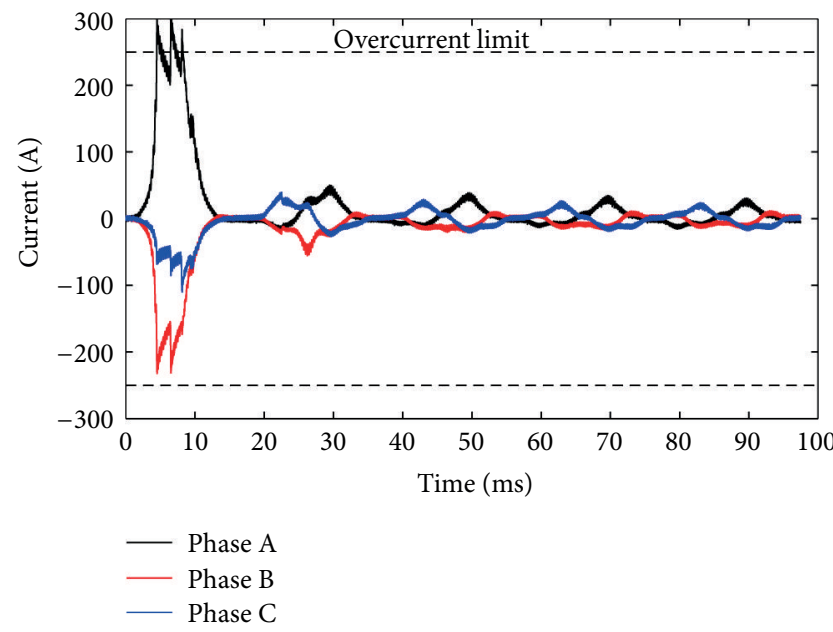

(c) $\alpha=0^{\circ} ; \beta=180^{\circ}$

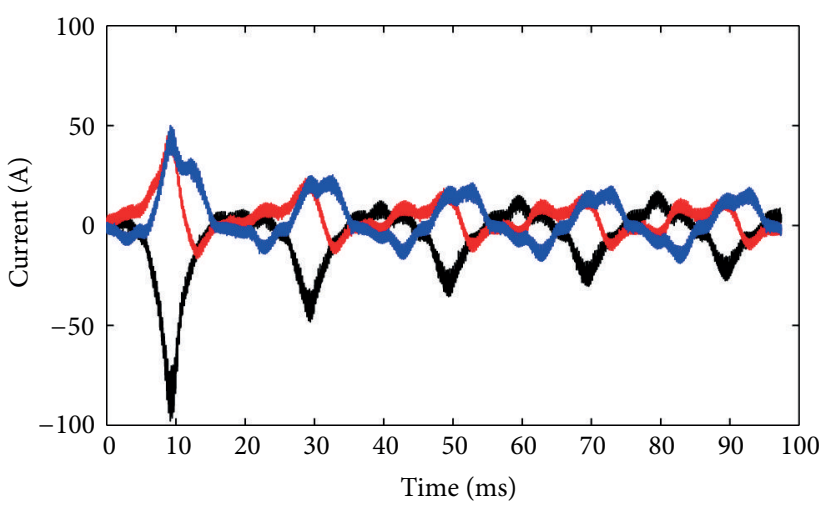

(b) $\alpha=180^{\circ} ; \beta=180^{\circ}$

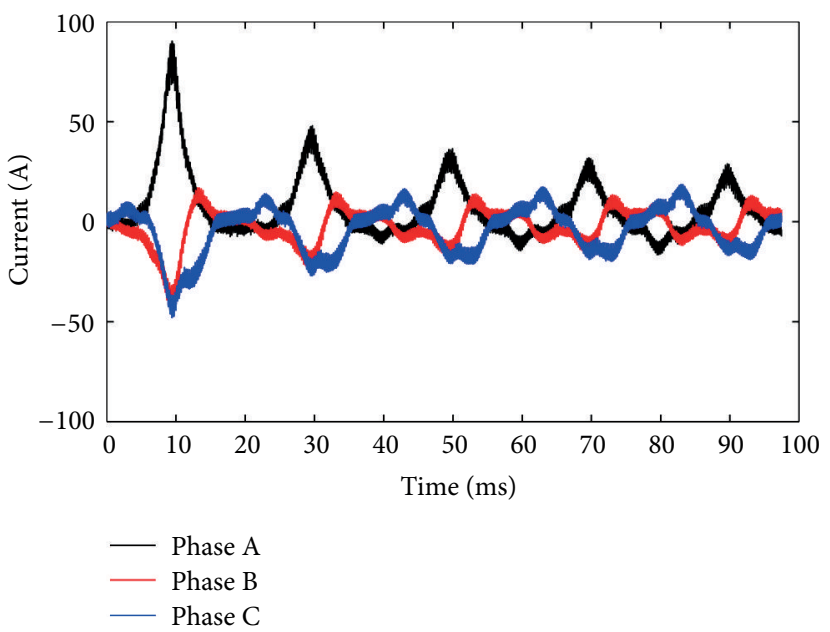

(d) $\alpha=0^{\circ} ; \beta=0^{\circ}$

FIGURE 5: Strategy 1, time plots for different firing angles $\alpha$ and stop angles $\beta$.

according to Figure 2(c), while the largest inrush currents may be avoided.

\section{Experimental Set-Up}

4.1. Hardware Implementation. A three-phase two-level voltage-source inverter (VSI) has been designed as shown in Figure 3(a). It is made from three dual-package 400GB126D insulated-gate bipolar transistor (IGBT) modules with 2SC0108T2Ax-17 driver boards mounted on top. These have in-built desaturation (desat) protections set to trigger $2.5 \mu \mathrm{s}$ after a fault detection of an overcurrent of $250 \mathrm{~A}$ or above. The de-sat protection circuit is shown in Figure 4(a). The collector-emitter voltage, $V_{\mathrm{CE}}$, across the IGBT is continuously detected, and if it goes above a set threshold value $V_{\text {th }}$ during conduction, this is recognized as a faulty current, and the IGBT is turned off. $V_{\mathrm{CE}}$ is a function of the the collector current $I_{C}$ as shown in Figure 4(b). The IGBT will be turned on again after a delay time, but after multiple fault detections, it will stop to avoid overheating.

The inverter is directly connected to a three-phase $345 \mathrm{~V} / 1 \mathrm{kV}$ YY-connected transformer, shown in Figure 3(b). The transformer ratings are given in Table 1.
TABLE 1: Transformer rating.

\begin{tabular}{lc}
\hline Power rating & $80 \mathrm{kVA}$ \\
Voltage ratio & $138 \mathrm{~V} / 1 \mathrm{kV}$ \\
Primary winding resistance & $6.8 \mathrm{~m} \Omega$ \\
Primary leakage reactance & $0.4 \mathrm{mH}$ \\
Secondary winding resistance & $48 \mathrm{~m} \Omega$ \\
Secondary leakage reactance & $8.8 \mathrm{mH}$ \\
Magnetizing impedance $(50 \mathrm{~Hz})$ & $0.368 \mathrm{H}$ \\
Magnetizing resistance $(50 \mathrm{~Hz})$ & $27.68 \Omega$ \\
\hline
\end{tabular}

4.2. Software Implementation. A compactRIO NI-9014 module with integrated RT-controller and FPGA chip has been used to implement grid control strategies and the proposed transformer magnetization strategies. The FPGA chip is of model Xilinx-5 [14] with an internal clock frequency of $40 \mathrm{MHz}$. The RT-controller is of the model NI-9022.

The VSI is controlled by sinusoidal pulse-width modulation (SPWM), where a sinusoidal reference waveform is compared with sawtooth carrier waveforms to generate the output logic to the IGBTs. It is possible to control the start angle $\alpha$ and stop angle $\beta$ as well as the voltage ramping slope. 


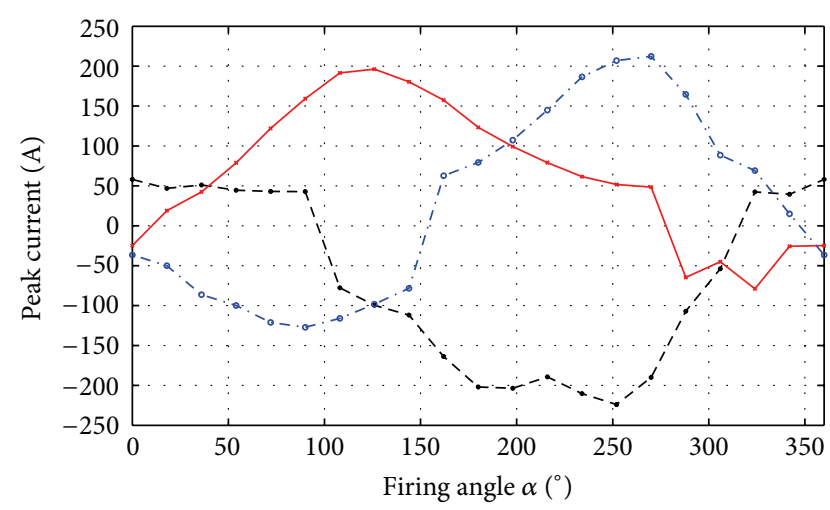

(a) $\beta=0^{\circ}$

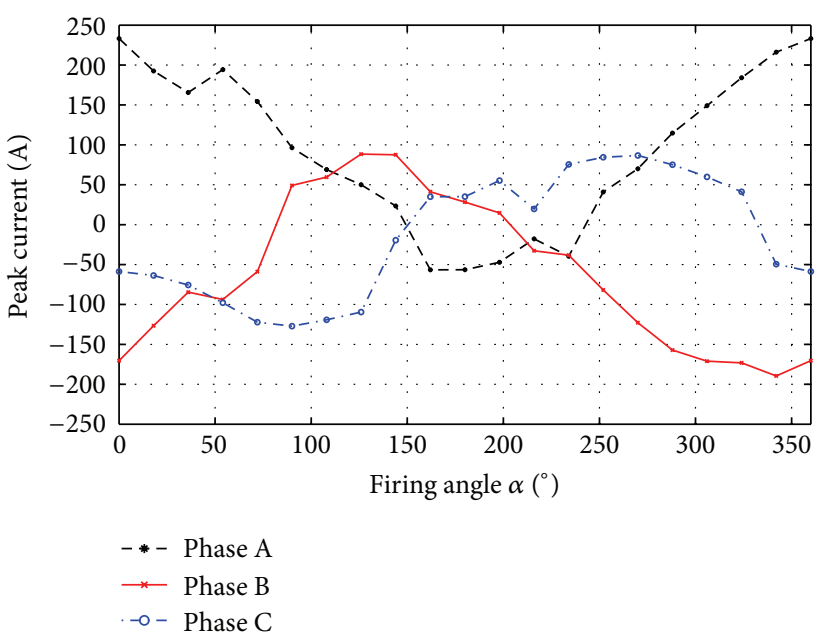

(c) $\beta=180^{\circ}$

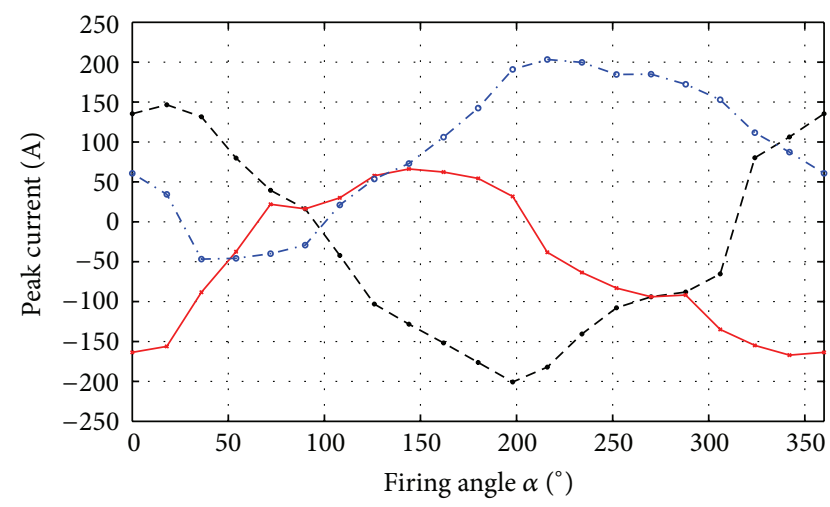

(b) $\beta=90^{\circ}$

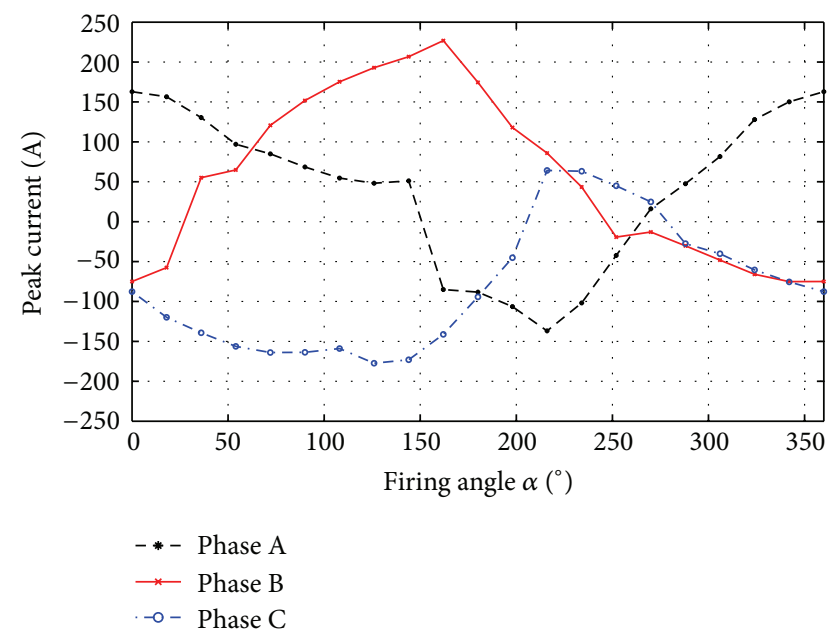

(d) $\beta=270^{\circ}$

FIGURE 6: Strategy 1, varying the firing angle $\alpha$ for different stop angles $\beta$.

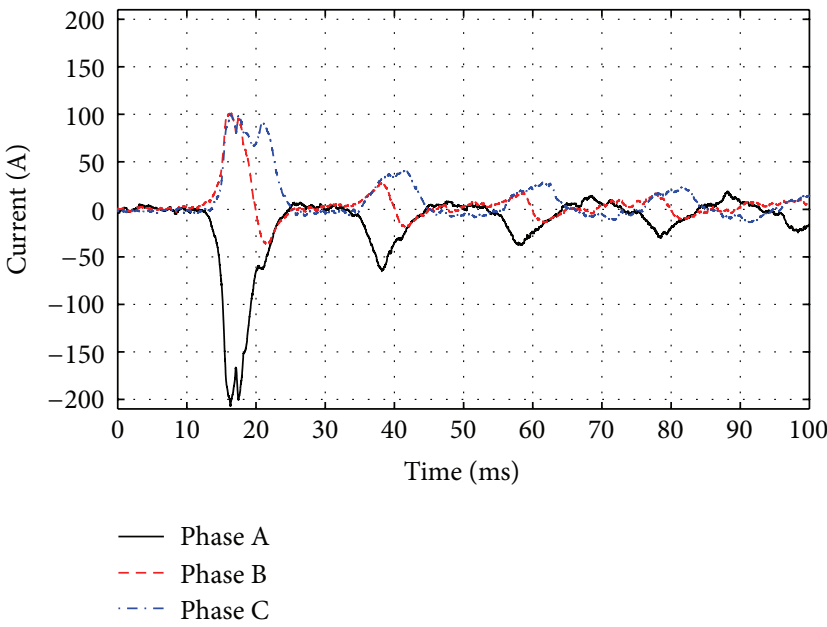

(a) $\alpha=0^{\circ}$

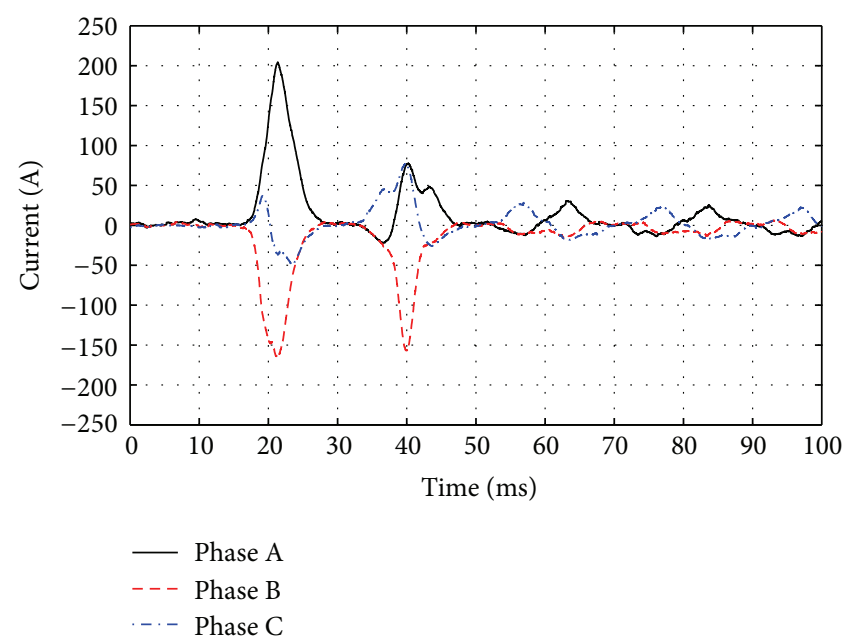

(b) $\alpha=180^{\circ}$

FIGURE 7: Strategy 2, time plots. 


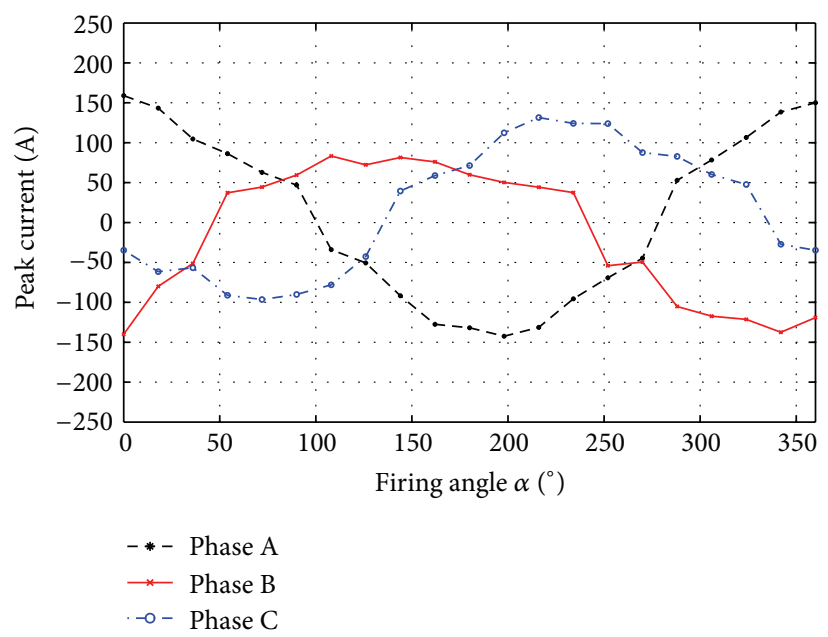

FIGURE 8: Strategy 2, varying the firing angle $\alpha$ with zero initial core flux.
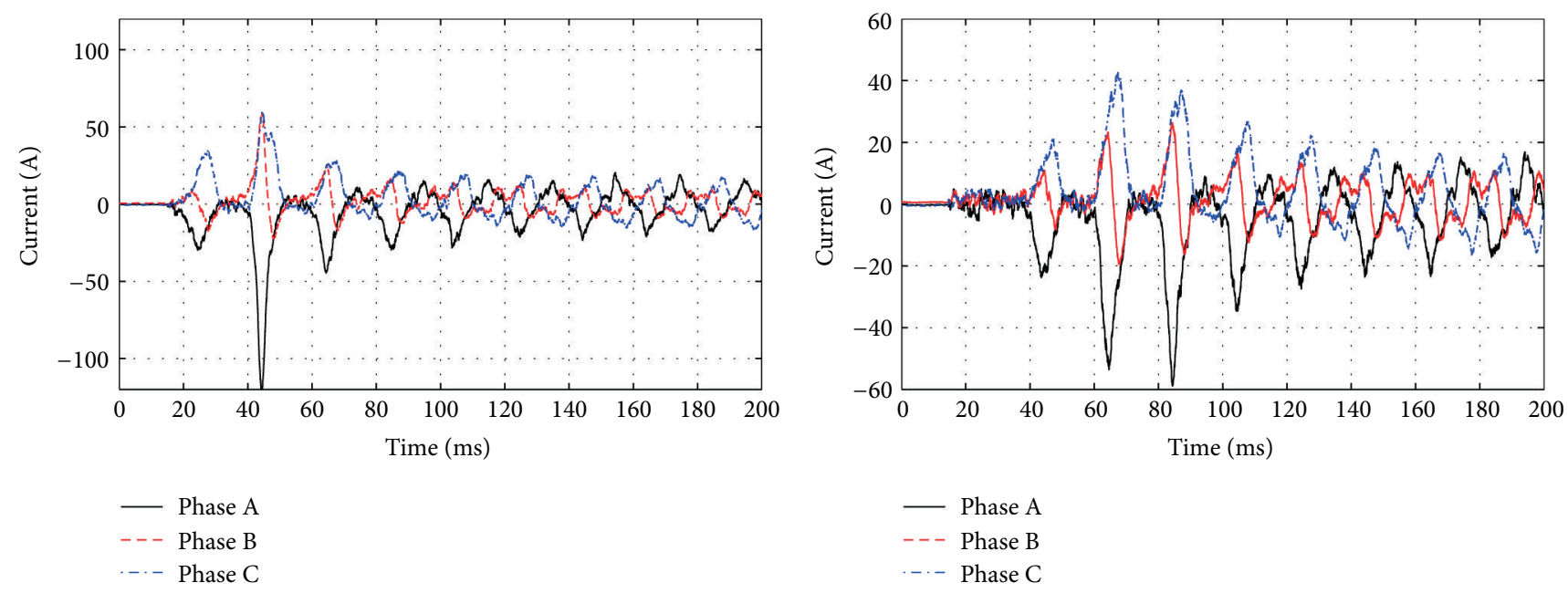

(a) 1 cycle

(b) 3 cycles

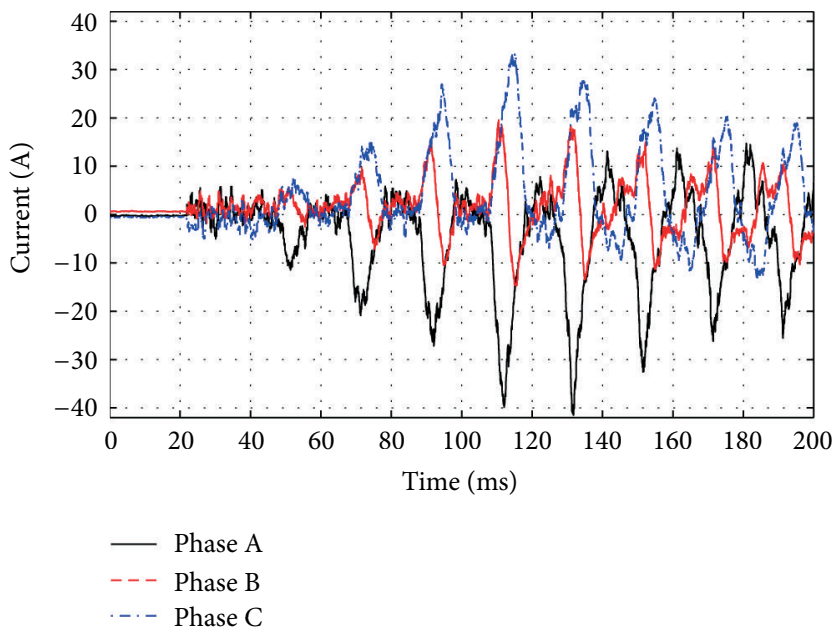

(c) 5 cycles

FIGURE 9: Strategy 3, varying the number of cycles from zero to full magnetization. 


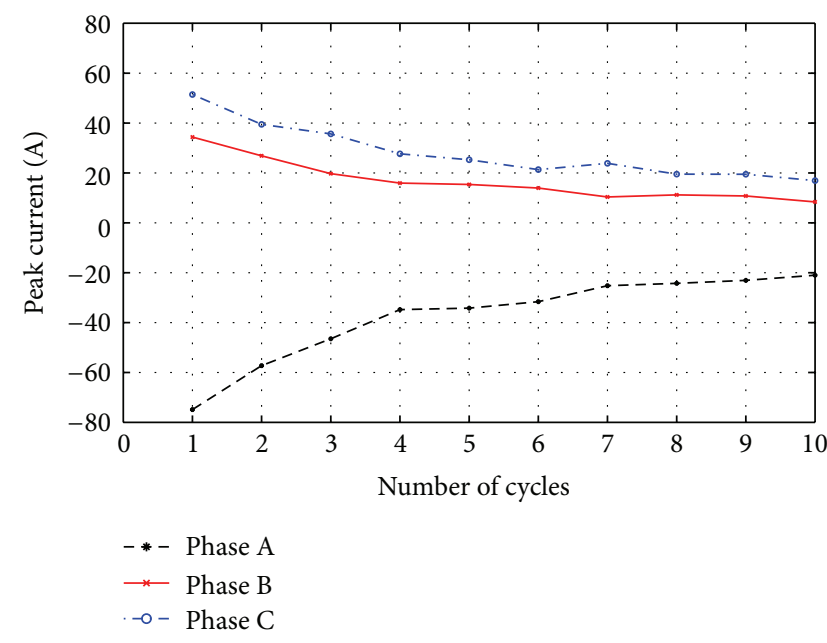

(a) $\beta=0^{\circ}$

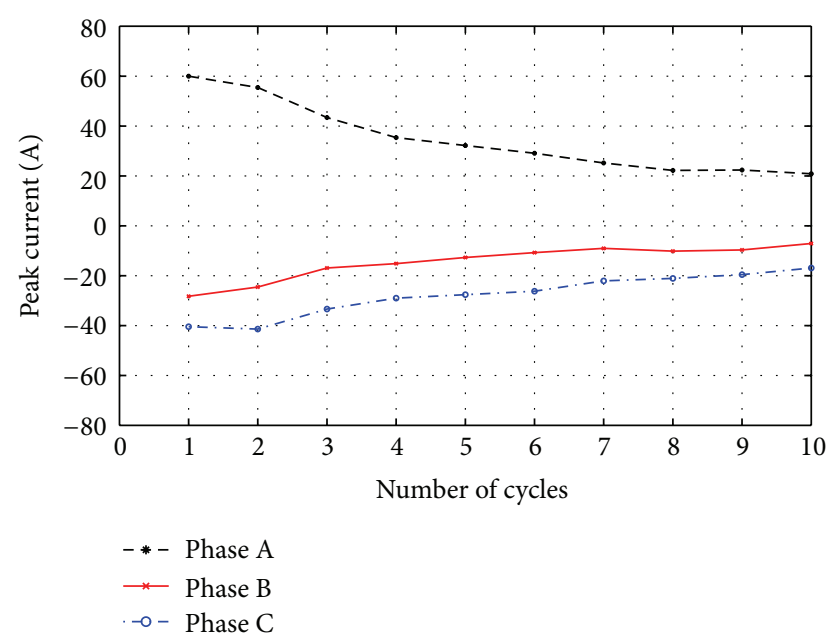

(b) $\beta=180^{\circ}$

FIGURE 10: Strategy 3, varying the number of cycles to full magnetization. The start angle $\alpha$ is always set to $0^{\circ}$, but it will have little impact on the current peaks for the voltage ramping strategy.

\section{Results and Discussion}

The transformer was magnetized to its rated voltage of $1 \mathrm{kV}$ using the three different strategies proposed above, while measuring the peak magnetizing inrush currents. In strategy 1 , the transformer was stopped at different angles $\beta$ to evaluate the variations in the remanent flux. In strategy 2 , this becomes redundant, as $\phi_{r}$ always converges to zero before start-up. In strategy $3, \beta=0^{\circ}$ and $\beta=180^{\circ}$ are used to evaluate $\phi_{\max ,-}$ and $\phi_{\max ,+}$.

5.1. Strategy 1 Results. In Figure 5, the magnetizing inrush currents are plotted for two different $\alpha$ and $\beta$ in phase A. These samples are shown to illustrate the worst scenarios with maximum remanent flux in the core. As expected, the highest inrush currents are obtained when $\alpha$ is shifted half a period from $\beta$, and here the peak currents easily reach above $250 \mathrm{~A}$. To minimize the peak currents for this strategy, $\alpha$ should be in phase with $\beta$, which here results in peak currents of about $100 \mathrm{~A}$. It is clear from Figures 5(a) and 5(c) how de-sat protection is activated, which otherwise could have resulted in much higher currents.

In Figure 6, the peak current values are sampled and displayed, for fixed values of $\beta$. The variation between phases is due to not only $\alpha$ and $\beta$, but also unbalances in the transformer core, where the center leg will have a lower reluctance path than the outer legs. This was not compensated for in the transformer design.

5.2. Strategy 2 Results. In strategy 2, the remanent flux is essentially removed, resulting in the special case of strategy 1 when $\beta=0^{\circ}$ for phase A. Also the remanent fluxes for phases $\mathrm{B}$ and $\mathrm{C}$ are removed, which was not the case in strategy 1 . In Figure 7, currents are displayed for the two worst case scenarios in phase $\mathrm{A}, \alpha=0^{\circ}$ and $\alpha=180^{\circ}$. The worst inrush currents are less than half compared to those in strategy 1 and never sufficiently high to trigger the de-sat protection. In Figure 8, the peak phase currents are shown while varying $\alpha$.

5.3. Strategy 3 Results. In Figure 9, the applied voltage starts from zero and is linearly ramped to 1 pu. In Figure 9(a), the ramping time duration is one fundamental cycle $(20 \mathrm{~ms})$; in Figure 9(b) this is increased to 3 cycles $(60 \mathrm{~ms})$ and in Figure 9(c) 5 cycles. $\beta$ was set to $0^{\circ}$ for all cases, but it has negligible impact for this strategy. Already at 1 cycle ramping time, the peak current has reduced by half compared to that in strategy 1 , and it continues to drop for longer time durations.

Inrush current peak vs. number of cycles is displayed in Figure 10. As the ramping time increases, the inrush currents are effectively removed.

\section{Conclusions}

The magnitude of the magnetizing inrush currents for a power transformer with direct VSI connection has been evaluated, where no external circuitry for the grid connection is required. Three magnetization strategies have been suggested and experimentally investigated: step response with remanent flux, step response without remanent flux, and voltage ramping. A de-sat protection is used to limit the highest currents. By removing the remanent flux, the peak inrush current is reduced to at least half in the worst cases. However, with voltage ramping, the peak currents may be more or less completely removed depending on the time duration of voltage ramping. All strategies are easy to implement in the FPGA-based control system.

\section{Conflict of Interests}

The authors declare that there is no conflict of interests regarding the publication of this paper. 


\section{Acknowledgments}

This project is supported by Statkraft AS, KIC InnoEnergyCIPOWER, Fortum oy, the Swedish Energy Agency, Draka Cable $\mathrm{AB}$, the Gothenburg Energy Research Foundation, Falkenberg Energy AB, the Wallenius Foundation, Helukabel, ProEnviro, Seabased AB, the Olle Engkvist Foundation, the J. Gust. Richert Foundation, $\AA$ ngpanneforeningen's Foundation for Research and Development, CF Environmental Fund, the Göran Gustavsson Research Foundation, and Vargöns Research Foundation. This support is gratefully acknowledged.

\section{References}

[1] M. Nagpal, T. G. Martinich, A. Moshref, K. Morison, and P. Kundur, "Assessing and limiting impact of transformer inrush current on power quality," IEEE Transactions on Power Delivery, vol. 21, no. 2, pp. 890-896, 2006.

[2] L.-C. Wu, C.-W. Liu, S.-E. Chien, and C.-S. Chen, "The effect of inrush current on transformer protection," in Proceedings of the 38th Annual North American Power Symposium (NAPS '06), pp. 449-456, Carbondale, Ill, USA, September 2006.

[3] F. Mekic, R. Girgis, Z. Gajic, and E. Nyenhuis, "Power transformer characteristics and their effect on protective relays," in Proceedings of the 33rd Western Protective Relay Conference, October 2006.

[4] J. H. Brunke and K. J. Fröhlich, "Elimination of transformer inrush currents by controlled switching. I: theoretical considerations," IEEE Transactions on Power Delivery, vol. 16, no. 2, pp. 276-280, 2001.

[5] J. H. Brunke and K. J. Fröhlich, "Elimination of transformer inrush currents by controlled switching. II: application and performance considerations," IEEE Transactions on Power Delivery, vol. 16, no. 2, pp. 281-285, 2001.

[6] Y. Cui, S. G. Abdulsalam, S. Chen, and W. Xu, "A sequential phase energization technique for transformer inrush current reduction. I: simulation and experimental results," IEEE Transactions on Power Delivery, vol. 20, no. 2, pp. 943-949, 2005.

[7] W. Xu, S. G. Abdulsalam, Y. Cui, and X. Liu, "A sequential phase energization technique for transformer inrush current reduction. II: theoretical analysis and design guide," IEEE Transactions on Power Delivery, vol. 20, no. 2, pp. 950-957, 2005.

[8] L. Cipcigan, W. Xu, and V. Dinavahi, "A new technique to mitigate inrush current caused by transformer energization," in Proceedings of the IEEE Power Engineering Society Summer Meeting, vol. 1, pp. 570-574, Chicago, ILL, USA, July 2002.

[9] M. S. J. Asghar, "Elimination of inrush current of transformers and distribution lines," in Proceedings of the 1996 International Conference on Power Electronics, Drives \& Energy Systems for Industrial Growth (PEDES '96), vol. 2, pp. 976-980, New Delhi, India, January 1996.

[10] K. Shinohara, K. Yamamoto, K. Iimori, Y. Minari, O. Sakata, and M. Miyake, "Compensation for magnetizing inrush currents in transformers using a PWM inverter," Electrical Engineering in Japan, vol. 140, no. 2, pp. 53-64, 2002.

[11] A. Rasic, G. Herold, and U. Krebs, "Fast connection /reconnection of the VSC to the power network," in Proceedings of the European Conference on Power Electronics and Applications (EPE '07), Aalborg, Denmark, September 2007.
[12] R. Ekstrom, S. Apelfrojd, and M. Leijon, "Transformer magnetization losses using a non-filtered voltage-source inverter," Advances in Power Electronics, vol. 2013, Article ID 261959, 7 pages, 2013.

[13] D. Povh and W. Schultz, "Analysis of overvoltages caused by transformer magnetizing inrush current," IEEE Transactions on Power Apparatus and Systems, vol. 97, no. 4, pp. 1355-1365, 1978.

[14] Xilinx Data Book, 2006, http://www.xilinx.com. 

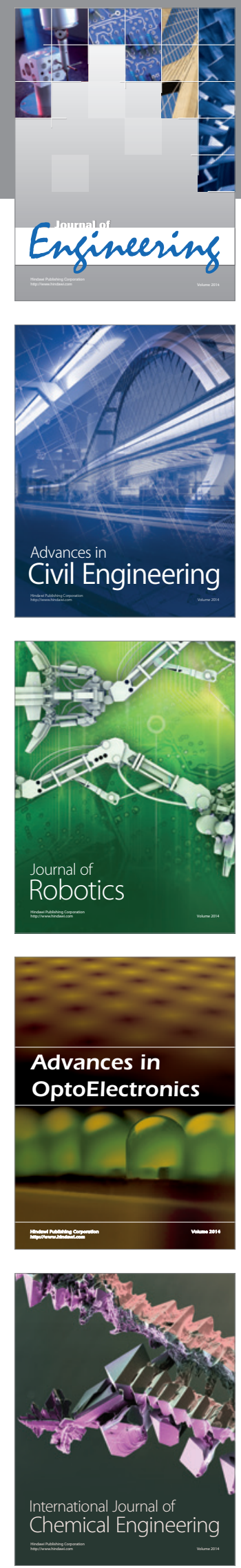

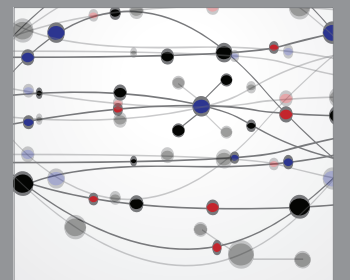

The Scientific World Journal
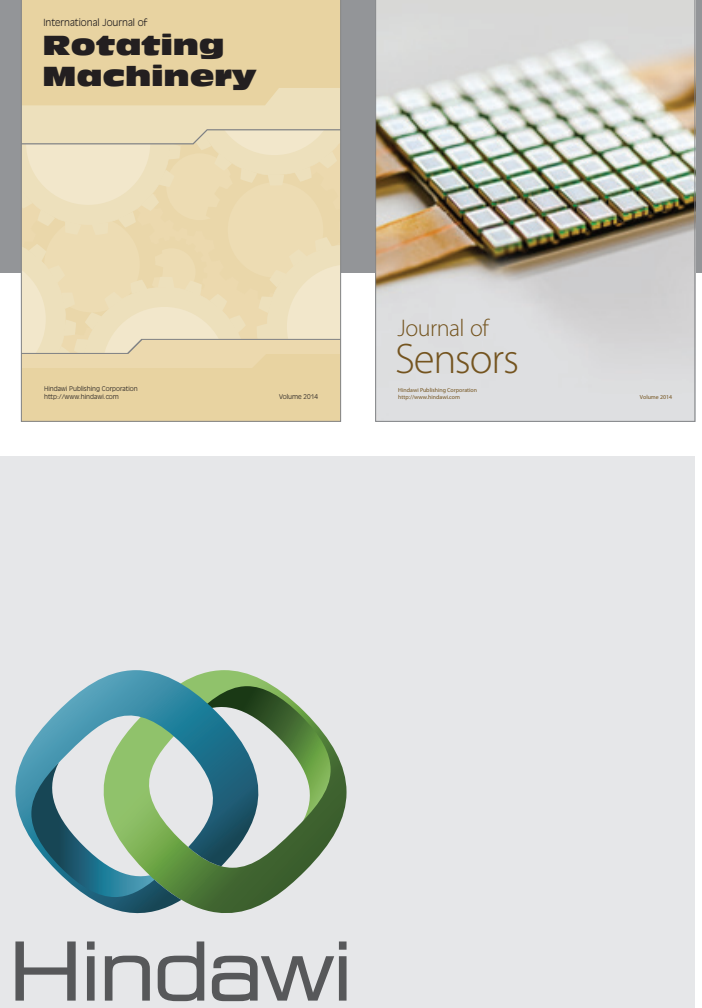

Submit your manuscripts at http://www.hindawi.com
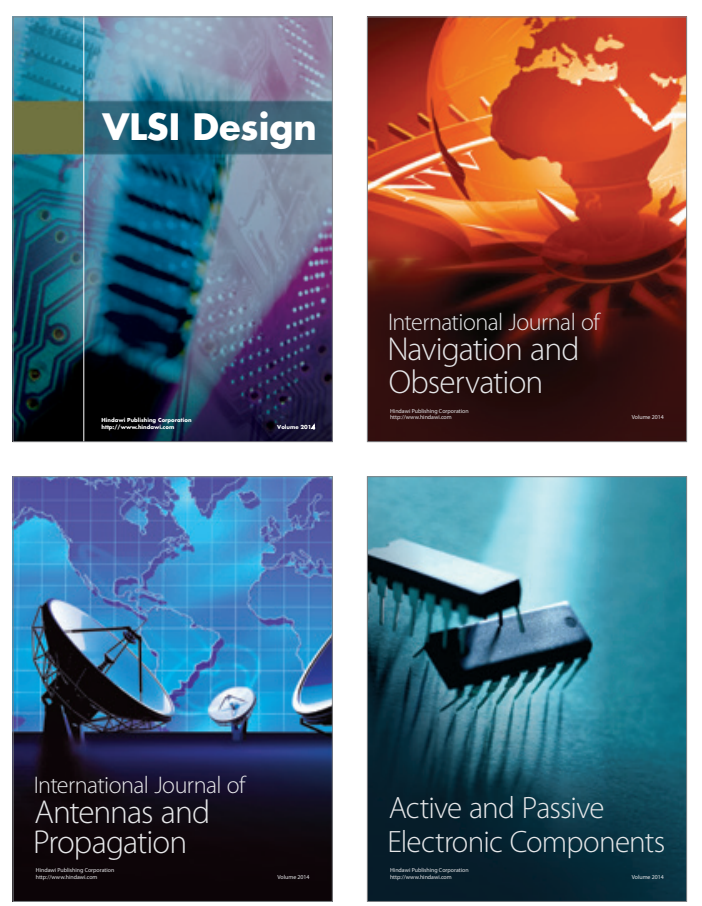
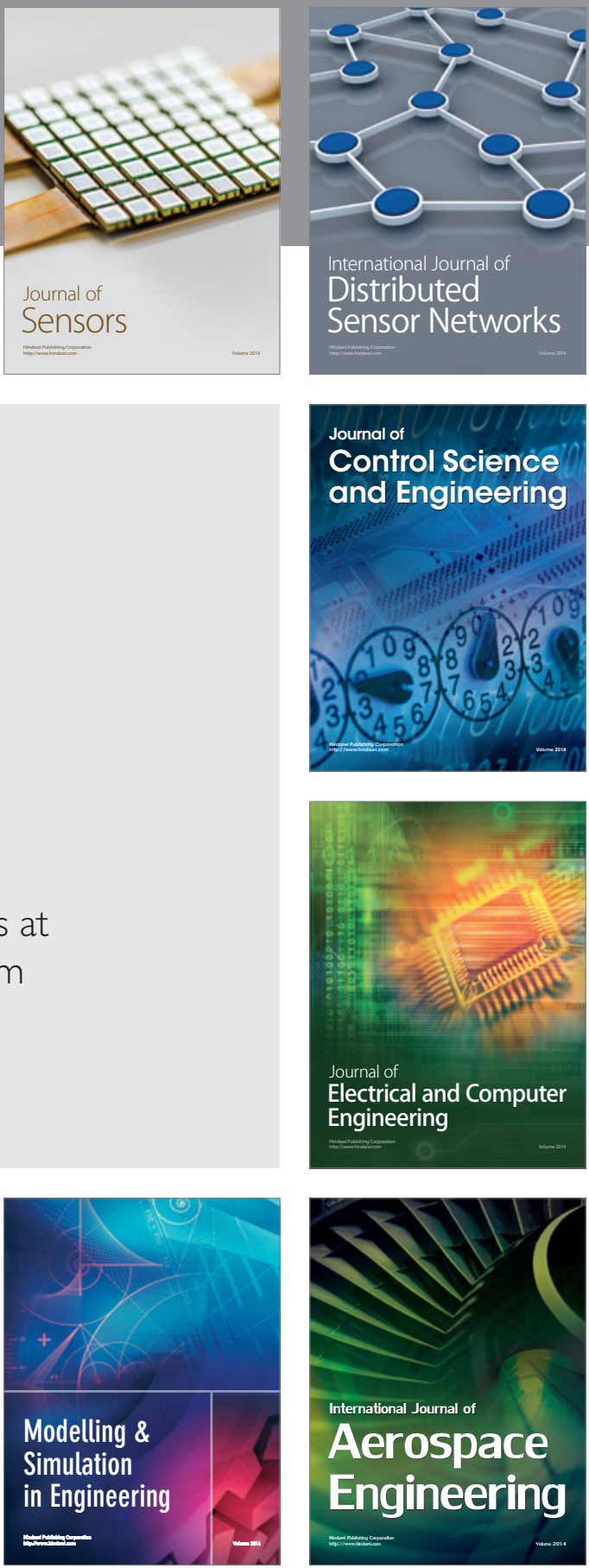

Journal of

Control Science

and Engineering
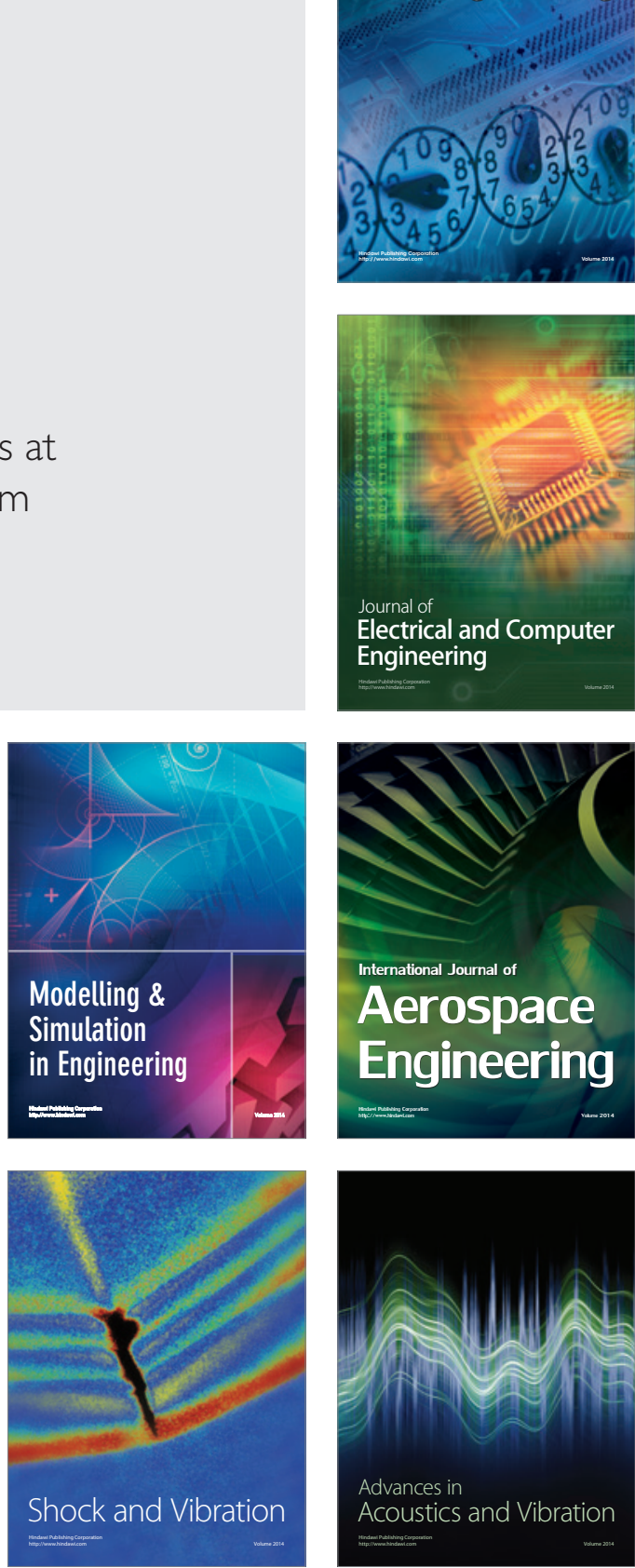